\title{
Role of physiotherapy and patient education in lymphedema control following breast cancer
}

\section{surgery}

\author{
Shiang-Ru Lu' \\ Rong-Bin Hong ${ }^{2}$ \\ Willy Chou ${ }^{3,4}$ \\ Pei-Chi Hsiao ${ }^{3,4}$ \\ 'Department of Neurology, Kaohsiung \\ Medical University Hospital, \\ Kaohsiung, Taiwan; ${ }^{2}$ Departments of \\ Physical Medicine and Rehabilitation, \\ Chi-Mei Medical Center \\ Liouying Campus, Tainan, Taiwan; \\ ${ }^{3}$ Department of Physical Medicine \\ and Rehabilitation, Chi-Mei Medical \\ Center, Tainan, Taiwan; ${ }^{4}$ Department \\ of Recreation and Health Care \\ Management, Chia Nan University of \\ Pharmacy and Science, Tainan, Taiwan
}

Correspondence: Pei-Chi Hsiao Department of Physical Medicine and Rehabilitation, Chi-Mei Medical Center, No 90I, Zhonghua Road, Yongkang District, Tainan 71004, Taiwan Tel +886628I 28II ext 53745 Email peichi 1227@gmail.com

\author{
This article was published in the following Dove Press journal: \\ Therapeutics and Clinical Risk Management \\ 25 February 2015 \\ Number of times this article has been viewed
}

Introduction: This retrospective cohort study evaluated whether education in combination with physiotherapy can reduce the risk of breast cancer-related lymphedema (BCRL).

Methods: We analyzed 1,217 women diagnosed with unilateral breast cancer between January 2007 and December 2011 who underwent tumor resection and axillary lymph node dissection. The patients were divided into three groups: Group A ( $n=415)$, who received neither education nor physiotherapy postsurgery; Group B $(n=672)$, who received an educational program on BCRL between Days 0 and 7 postsurgery; and Group C ( $n=130)$, who received an educational program on BCRL between Days 0 and 7 postsurgery, followed by a physiotherapy program. All patients were monitored until October 2013 to determine whether BCRL developed. BCRL risk factors were evaluated using Cox proportional hazards models.

Results: During the follow-up, 188 patients (15.4\%) developed lymphedema, including 77 $(18.6 \%)$ in Group A, 101 (15.0\%) in Group B, and 10 (7.7\%) in Group C $(P=0.010)$. The median period from surgery to lymphedema was 0.54 years (interquartile range $=0.18-1.78$ ). The independent risk factors for BCRL included positive axillary lymph node invasion, a higher $(>20)$ number of dissected axillary lymph nodes, and having undergone radiation therapy, whereas receiving an educational program followed by physiotherapy was a protective factor against BCRL (hazard ratio $=0.35,95 \%$ confidence interval $=0.18-0.67, P=0.002$ ).

Conclusion: Patient education that begins within the first week postsurgery and is followed by physiotherapy is effective in reducing the risk of BCRL in women with breast cancer.

Keywords: breast cancer, lymphedema, physical therapy, education

\section{Introduction}

Lymphedema refers to the accumulation of protein-rich fluid in the interstitial space caused by a compromised lymphatic system. Breast cancer-related lymphedema (BCRL) of the upper limbs is a common complication following breast cancer surgery. The incidence of BCRL was approximately $20 \%$ in breast cancer survivors who underwent tumor resection with axillary lymph node dissection (ALND). ${ }^{1}$ BCRL may appear immediately or years posttreatment, with the majority diagnosed during the first 3 years. ${ }^{2}$ Lymphedema causes limb and shoulder pain, heaviness, tightness, and decreased range of motion. Gross and fine motor skills are affected, the daily functions are restricted, and psychosocial relationship is impeded. ${ }^{3}$

Previous studies have identified several risk factors associated with the occurrence of BCRL, which include the following: arm infection, inflammation, or injury;, ${ }^{2,4}$ overweight or weight gain;,2,-7 aging; ${ }^{4}$ surgery on the dominant arm; ${ }^{4,6}$ level of hand use ${ }^{5}$ a higher number of removed axillary lymph nodes $;{ }^{7}$ being married $;{ }^{7}$ having received a mastectomy ${ }^{8}$ ALND,${ }^{8}$ radiation therapy $, 6,8$ or chemotherapy ${ }^{7}$ pathological status of the 
lymph nodes, ${ }^{6,8}$ and menopause. ${ }^{6}$ These disease- and treatmentrelated factors cause tissue scarring and fibrosis. Fibrosis impairs the proliferation of lymphatic endothelial cells and compromises lymphatic regeneration. ${ }^{9}$ Abnormal lymphatic microarchitecture and functions lead to a reversed lymphatic flow from the collecting vessels to the lymphatic capillaries and consequently the development of lymphedema. ${ }^{10}$ At later stages, a complex interaction between lymphangiogenesis, inflammation, fibrosis, and lipid metabolism results in the proliferation and deposition of fibrotic and adipose tissues. ${ }^{11,12}$

Managing BCRL involves the practice of risk-reduction behavior, skin care, manual lymphatic drainage (MLD), exercise, and external compression devices. ${ }^{13}$ The mainstay among these strategies continues to be symptom control. Early postoperative rehabilitation programs can improve the range of shoulder motion, ${ }^{14}$ but whether they can reduce the risk of BCRL remains unclear. Only two prospective studies have shown that breast cancer patients who participated in early postoperative physiotherapy and an educational program had lower BCRL rates (5\%-7\%) compared with those who did not $(20 \%-25 \%){ }^{15,16}$

The purpose of this study was to determine the effect of early postoperative education and physiotherapy in reducing the occurrence of secondary upper-limb lymphedema in women who underwent breast cancer surgery and ALND, and to compare this effect with those of education alone and complete nonintervention.

\section{Methods}

\section{Data source}

We performed a retrospective cohort analysis based on cancer registry data from Chi-Mei Medical Center (CMMC). This registry has prospectively collected and followed up cancer patients diagnosed at CMMC since 2002 and at the center's Liou-Ying branch since 2006. The demographics, diagnoses, and clinical characteristics of cancers, types of cancer treatment (operation, chemotherapy, or radiation), responsiveness to treatment (remission, recurrence, or metastasis), and outcome (survival or death) were recorded. Additional clinical information not included in the registry was obtained retrospectively from the medical charts. The CMMC Institutional Review Board reviewed the medical ethics of this study and approved the study before it was commenced.

\section{Patients}

This study included women who were diagnosed with Stages 0-3 breast cancer for the first time between January 1, 2007, and December 31, 2011, and who underwent tumor resection and ALND as their primary therapy. We excluded patients with bilateral breast cancer, patients who already developed lymphedema before surgery, and patients with neurological diseases that affected ipsilateral arm, shoulder, or axilla mobility.

During the study period, 1,233 women fulfilled our inclusion criteria. After the exclusion of the 11 women who had bilateral breast cancer, and five women who fulfilled other exclusion criteria, the remaining 1,217 patients qualified as our study population. These patients were further divided into three groups: Group A, who received neither education nor physiotherapy postsurgery; Group B, who received an educational program on lymphedema between Days 0 and 7 postsurgery; and Group C, who received an educational program between Days 0 and 7 postsurgery, followed by physiotherapy.

\section{Educational program and physical therapy}

Surgeons determined whether patients required rehabilitation services in the postoperative period, and the consulted rehabilitation physician selected the appropriate program for the patient. A patient-centered educational program, if requested, was conducted in a consistent manner. A specialized physiotherapist provided instructions with printed materials to the patients. The educational program was primarily based on a published guideline ${ }^{17}$ and materials from the National Lymphedema Network. ${ }^{18}$ The educational program provided information on the lymphatic system, the symptoms and signs of lymphedema, and suggestions for preventing lymphedema, such as engaging in postoperative exercise, modifying activities, massaging the scar tissue, maintaining a healthy body weight, and avoiding trauma to or infection or venipuncture of the limb. The physiotherapy program, if requested, included the following treatments: breathing exercise, postsurgical positioning, massaging of scar tissue and stretching of soft tissue, mobilization of the shoulders, and shoulder and upper extremity exercises (Table S1). Physiotherapy was conducted under the instruction of physiotherapists, began during the first week postsurgery in the hospital, and was continued at outpatient clinics postdischarge. The duration of each session was 30 minutes, and the program was administered twice weekly. The total number of physiotherapy sessions varied according to the clinical condition of each patient.

\section{Outcome}

The outcome of this study was the occurrence of lymphedema in the upper extremity in the period after surgery 
to October 31, 2013. The diagnosis of lymphedema was based on clinical examination (ie, a limb-to-limb difference of $\geq 2 \mathrm{~cm}$ in circumference at any measurement site along the upper limb). The staging of lymphedema was performed according to the criteria defined by the International Society of Lymphology, which include the following: Stage 1: spontaneously reversible edema; Stage 2: spontaneously irreversible edema; and Stage 3: irreversible edema and fibrosis or lymphostatic elephantiasis. ${ }^{19}$

\section{Variables of interest}

The variables of interest in this study can be categorized as patient-related, disease-related, and treatment-related variables. The patient-related variables included age at breast cancer diagnosis, body mass index (BMI), and menstrual status. The disease-related variables included the Classification of Malignant Tumors (TNM) stage (Stages 0-3), histologic grade of breast cancer (Grades 1-3), status of axillary lymph node invasion (negative or positive), and tumor size. TNM staging was based on the sixth edition of the American Joint Committee on Cancer's AJCC Cancer Staging Manual, ${ }^{20}$ and the histologic grading was based on the Nottingham Score of breast cancer. ${ }^{21}$ The treatment-related variables included the type of surgery (breast-conserving surgery [BCS], simple mastectomy, and modified radical mastectomy [MRM]), the number of dissected axillary lymph nodes, and receiving adjuvant treatment (radiation therapy or chemotherapy).

\section{Statistical analysis}

The patient-related, disease-related, and treatment-related variables were summarized using descriptive statistics. Continuous variables were expressed as means with standard deviations or medians with interquartile ranges (IQRs) when appropriate. To compare the various patient groups, we employed analysis of variance on each patient's age and BMI, and the Kruskal-Wallis test for follow-up duration and time to lymphedema occurrence. We analyzed the categorical variables by using Pearson's chi-squared test or Fisher's exact test and the log-rank test. These categorical variables included age group $(<50$ years, $50-65$ years, or $>65$ years), BMI group $\left(<27 \mathrm{~kg} / \mathrm{m}^{2}\right.$ or $\left.\geq 27 \mathrm{~kg} / \mathrm{m}^{2}\right)$, menstrual status (reached menopause or not), TNM stage (Stages $0-2$ or 3), histologic grade (Grade 1, 2, or 3), axillary lymph node invasion (negative or positive), tumor size $(<2 \mathrm{~cm}, 2-5 \mathrm{~cm}$, or $>5 \mathrm{~cm})$, surgery type (BCS, simple mastectomy, or MRM), number of dissected axillary lymph nodes (dichotomized as $\leq 20$ or $>20$ ), and receiving adjuvant radiation therapy or chemotherapy (no or yes). Univariate and multivariate Cox proportional hazards regression models were used to evaluate the relative prognostic significance of the variables in predicting the occurrence of upper-limb lymphedema. ${ }^{22}$ Based on 1-year steps, the entry time was the date of breast cancer surgery and the exit time was the occurrence of postsurgical upper-limb lymphedema during the follow-up. Only variables with statistical significance in the univariate analysis were included in the multivariate analysis. The results of the multivariate analysis were adjusted for all of the variables and presented as hazard ratios (HRs) and 95\% confidence intervals (CIs). To estimate the probability of lymphedema occurrence over time, the Kaplan-Meier method was employed and compared using a log-rank test. Statistical significance was set at $P<0.05$ for all analyses, which were conducted using SPSS software, version 19.0 (SPSS Inc., Chicago, IL, USA).

\section{Results}

The 1,217 patients comprised 415 patients (34.1\%) in Group A, who received neither the educational program nor physiotherapy, 672 patients $(55.2 \%)$ in Group B, who received only the educational program, and 130 patients $(10.7 \%)$ in Group C, who received both the educational program and physiotherapy. The median number of physiotherapy in Group C was 12 sessions (IQR $=6-48$ ). Table 1 summarizes the patient demographics and clinical characteristics. The mean age for all patients when breast cancer was first diagnosed was $52.28 \pm 11.25$ years (range $=25-92$ ), and their mean BMI was $24.12 \pm 3.70 \mathrm{~kg} / \mathrm{m}^{2}$ (range $=14.82-41.98$ ). More than half $(n=660,54.2 \%)$ of the patients were postmenopausal. Most patients $(n=873,71.7 \%)$ received MRM as their primary surgery. The demographics and clinical characteristics did not differ substantially between the groups, except for surgery type (Table 1).

The patients were monitored postsurgery for a median duration of 2.88 years (IQR $=1.78-4.33$ ). During the follow-up, 188 patients (15.4\%) developed lymphedema, comprising 116 patients (61.7\%) with Stage 1 lymphedema, 60 patients $(31.9 \%)$ with Stage 2 lymphedema, and 12 patients $(6.4 \%)$ with Stage 3 lymphedema. The rates of lymphedema occurrence were $18.6 \%$ in Group A $(n=77)$, $15.0 \%$ in Group B $(n=101)$, and $7.7 \%$ in Group C $(n=10)$ $(P=0.010$, Table 2$)$. The median period from surgery to initial lymphedema swelling was 0.54 years $(\mathrm{IQR}=0.18-1.78)$, and initial swelling most commonly occurred within the first year postsurgery $(n=120,63.8 \%)$, followed by the second year $(n=30,16.0 \%)$ and the third year $(n=20,10.6 \%)$. 
Table I Patient demographics and clinical characteristics

\begin{tabular}{|c|c|c|c|c|c|}
\hline \multirow[t]{2}{*}{ Variables } & \multirow{2}{*}{$\begin{array}{l}\text { Group A } \\
\text { No education or } \\
\text { physiotherapy } \\
(n=4 \mid 5)\end{array}$} & \multirow{2}{*}{$\begin{array}{l}\text { Group B } \\
\begin{array}{l}\text { Education only } \\
(n=672)\end{array}\end{array}$} & \multirow{2}{*}{$\begin{array}{l}\text { Group C } \\
\text { Physiotherapy and } \\
\text { education }(n=130)\end{array}$} & \multirow[t]{2}{*}{ All patients } & \multirow[t]{2}{*}{ P-value* } \\
\hline & & & & & \\
\hline Mean age (years) & $51.79 \pm 11.97$ & $52.67 \pm \mid 1.01$ & $51.88 \pm 10.08$ & $52.28 \pm 11.25$ & 0.418 \\
\hline Mean BMI $\left(k g / m^{2}\right)$ & $23.98 \pm 3.63$ & $24.24 \pm 3.75$ & $23.91 \pm 3.65$ & $24.12 \pm 3.70$ & 0.438 \\
\hline \multicolumn{6}{|l|}{ Age group (years), n (\%) } \\
\hline$<50$ & $215(51.8 \%)$ & $318(47.3 \%)$ & $65(50.0 \%)$ & $598(49.1 \%)$ & 0.110 \\
\hline $50-65$ & $136(32.8 \%)$ & $249(37.1 \%)$ & $54(41.5 \%)$ & $439(36.1 \%)$ & \\
\hline$>65$ & $64(15.4 \%)$ & $105(15.6 \%)$ & II (8.5\%) & $180(14.8 \%)$ & \\
\hline \multicolumn{6}{|l|}{ BMI $\left(k g / m^{2}\right), n(\%)$} \\
\hline$<27$ & $343(82.7 \%)$ & $533(79.3 \%)$ & $105(80.8 \%)$ & 981 (80.6\%) & 0.401 \\
\hline$\geq 27$ & $72(17.3 \%)$ & $139(20.7 \%)$ & 25 (19.2\%) & $236(19.4 \%)$ & \\
\hline \multicolumn{6}{|l|}{ Menstrual status, n (\%) } \\
\hline No menopause & $200(48.2 \%)$ & $298(44.3 \%)$ & $59(45.4 \%)$ & $557(45.8 \%)$ & 0.463 \\
\hline Menopause & $215(51.8 \%)$ & $374(55.7 \%)$ & $71(54.6 \%)$ & $660(54.2 \%)$ & \\
\hline \multicolumn{6}{|l|}{ TNM stage, $\mathrm{n}(\%)$} \\
\hline $0-2$ & $326(78.6 \%)$ & $503(74.9 \%)$ & $92(70.8 \%)$ & 921 (75.7\%) & 0.148 \\
\hline 3 & 89 (21.4\%) & $169(25.1 \%)$ & $38(29.2 \%)$ & $296(24.3 \%)$ & \\
\hline \multicolumn{6}{|l|}{ Histologic grade, n (\%) } \\
\hline 1 & $63(15.2 \%)$ & $122(18.2 \%)$ & $22(16.9 \%)$ & 207 (17.0\%) & 0.404 \\
\hline 2 & $243(58.6 \%)$ & $400(59.5 \%)$ & $72(55.4 \%)$ & $715(58.8 \%)$ & \\
\hline 3 & $109(26.3 \%)$ & $150(22.3 \%)$ & $36(27.7 \%)$ & 295 (24.2\%) & \\
\hline \multicolumn{6}{|c|}{ Axillary lymph node invasion, n (\%) } \\
\hline Negative & $243(58.6 \%)$ & 394 (58.6\%) & $73(56.2 \%)$ & 710 (58.3\%) & 0.866 \\
\hline Positive & 172 (4I.4\%) & $278(41.4 \%)$ & $57(43.8 \%)$ & 507 (4I.7\%) & \\
\hline \multicolumn{6}{|l|}{ Tumor size (cm), n (\%) } \\
\hline$<2$ & 177 (42.7\%) & $306(45.5 \%)$ & $60(46.2 \%)$ & $543(44.6 \%)$ & 0.352 \\
\hline $2-5$ & 206 (49.6\%) & $300(44.6 \%)$ & 55 (42.3\%) & $56 \mid(46.1 \%)$ & \\
\hline$>5$ & $32(7.7 \%)$ & $66(9.8 \%)$ & 15 (II.5\%) & $113(9.3 \%)$ & \\
\hline \multicolumn{6}{|l|}{ Surgery type, n (\%) } \\
\hline $\mathrm{BCS}$ & $123(29.6 \%)$ & $152(22.6 \%)$ & $28(21.5 \%)$ & 303 (24.9\%) & $<0.001$ \\
\hline Simple mastectomy & $25(6.0 \%)$ & $11(1.6 \%)$ & $5(3.8 \%)$ & $4 \mathrm{I}(3.4 \%)$ & \\
\hline MRM & $267(64.3 \%)$ & $509(75.7 \%)$ & 97 (74.6\%) & $873(71.7 \%)$ & \\
\hline \multicolumn{6}{|c|}{ Number of dissected axillary lymph nodes, n (\%) } \\
\hline$\leq 20$ & $253(61.0 \%)$ & $386(57.4 \%)$ & 79 (60.8\%) & $718(59.0 \%)$ & $0.47 I$ \\
\hline$>20$ & $162(39.0 \%)$ & $286(42.6 \%)$ & $5 \mathrm{I}(39.2 \%)$ & $499(41.0 \%)$ & \\
\hline \multicolumn{6}{|l|}{ Adjuvant R/T, n (\%) } \\
\hline No & $233(56.1 \%)$ & $375(55.8 \%)$ & $64(49.2 \%)$ & $672(55.2 \%)$ & 0.346 \\
\hline Yes & $182(43.9 \%)$ & $297(44.2 \%)$ & $66(50.8 \%)$ & $545(44.8 \%)$ & \\
\hline \multicolumn{6}{|l|}{ Adjuvant C/T, n (\%) } \\
\hline No & $73(17.6 \%)$ & $123(18.3 \%)$ & $19(14.6 \%)$ & $215(17.7 \%)$ & 0.600 \\
\hline Yes & $342(82.4 \%)$ & $549(81.7 \%)$ & III (85.4\%) & $\mathrm{I}, 002(82.3 \%)$ & \\
\hline
\end{tabular}

Notes: $* P$-value is from analysis of variance for the continuous variable (age, BMI) or from chi-squared test for the categorical variables in Groups $\mathrm{A}-\mathrm{C}$.

Abbreviations: BMI, body mass index; BCS, breast-conserving surgery; MRM, modified radical mastectomy; R/T, radiation therapy; C/T, chemotherapy; TNM, Classification of Malignant Tumors.

To evaluate the risk factors associated with the occurrence of postsurgical lymphedema, a univariate analysis was conducted (Table 3 ). The following factors were associated with lymphedema: a high BMI ( $\left.\geq 27 \mathrm{~kg} / \mathrm{m}^{2}, \mathrm{HR}=1.47\right)$, late TNM stage (Stage 3, HR $=2.04$ ), positive axillary lymph node invasion ( $\mathrm{HR}=2.15$ ), large tumor size ( $>5 \mathrm{~cm}, \mathrm{HR}=2.00$ ), a higher number $(>20)$ of dissected axillary lymph nodes ( $\mathrm{HR}=1.60)$, and receiving adjuvant radiation therapy $(\mathrm{HR}=1.99)$ and chemotherapy $(\mathrm{HR}=2.17)$. By contrast, receiving the postoperative educational program followed by physiotherapy was negatively associated with lymphedema occurrence ( $\mathrm{HR}=0.39)$. Other factors, such as age, menstrual status, histologic grade of tumor, surgery type, and receiving the educational program alone, did not have predictive values for the occurrence of lymphedema (Table 3).

In the multivariate analysis, the following variables were associated with an increased risk of lymphedema (Table 4): positive axillary lymph node invasion ( $\mathrm{HR}=1.55,95 \%$ 
Table 2 Patient outcomes

\begin{tabular}{|c|c|c|c|c|c|}
\hline \multirow[t]{2}{*}{ Variable } & \multirow{2}{*}{$\begin{array}{l}\text { Group A } \\
\text { No education or } \\
\text { physiotherapy } \\
(n=4 \mid 5)\end{array}$} & \multirow{2}{*}{$\begin{array}{l}\text { Group B } \\
\begin{array}{l}\text { Education only } \\
(n=672)\end{array}\end{array}$} & \multirow{2}{*}{$\begin{array}{l}\text { Group C } \\
\text { Physiotherapy } \\
\text { and education } \\
(n=130)\end{array}$} & \multirow[t]{2}{*}{ All patients } & \multirow[t]{2}{*}{$P$-value* } \\
\hline & & & & & \\
\hline $\begin{array}{l}\text { Median follow-up duration } \\
\text { (years) (IQR) }\end{array}$ & $2.93(1.63-4.63)$ & $2.79(1.78-4.25)$ & $3.15(2.14-4.16)$ & $2.88(1.78-4.33)$ & 0.183 \\
\hline $\begin{array}{l}\text { Median time to lymphedema } \\
\text { (years) (IQR) }\end{array}$ & $0.55(0.28-2.2 I)$ & $0.44(0.12-1.42)$ & $1.29(0.45-1.91)$ & $0.54(0.18-1.78)$ & 0.085 \\
\hline \multicolumn{6}{|l|}{ Lymphedema, n (\%) } \\
\hline No & $338(81.4 \%)$ & $57 \mid(85.0 \%)$ & $120(92.3 \%)$ & I,029 (84.6\%) & 0.010 \\
\hline Yes & $77(18.6 \%)$ & 101 (15.0\%) & $10(7.7 \%)$ & $188(15.4 \%)$ & \\
\hline \multicolumn{6}{|l|}{ Lymphedema severity, n (\%) } \\
\hline Stage I & $42(54.5 \%)$ & $65(64.4 \%)$ & $9(90.0 \%)$ & $116(61.7 \%)$ & 0.069 \\
\hline Stages 2 and 3 & 35 (45.5\%) & $36(35.6 \%)$ & I (I0.0\%) & 72 (38.3\%) & \\
\hline
\end{tabular}

Notes: *P-value is from the Kruskal-Wallis test for comparisons of medians, or from chi-squared test or Fisher's exact test for comparisons of the categorical variables in Groups A-C.

Abbreviation: IQR, interquartile range.

$\mathrm{CI}=1.06-2.28, P=0.025)$, a higher $(>20)$ number of dissected axillary lymph nodes ( $\mathrm{HR}=1.40,95 \% \mathrm{CI}=1.05-1.88$, $P=0.024)$, and receiving radiation therapy (HR $=1.53$, $95 \% \mathrm{CI}=1.11-2.11, P=0.010)$. Receiving the educational program with physiotherapy remained a protective factor against lymphedema ( $\mathrm{HR}=0.35,95 \% \mathrm{CI}=0.18-0.67$, $P=0.002$ ) (Table 4). The Kaplan-Meier plots indicated that the patients in Group C exhibited a significantly lower risk of lymphedema during the follow-up compared with Groups A and B (log-rank test: $P=0.014$, Figure 1).

\section{Discussion}

Among the women with breast cancer who were examined in this study, $15.4 \%$ developed upper-limb lymphedema postsurgery, including 18.6\% in Group A, 15.0\% in Group B, and $7.7 \%$ in Group C. Consistent with previous studies, ${ }^{1}$ we found that having received a more extensive lymph node dissection, tumor invasion of the lymph nodes, and having received radiation therapy were significant risk factors for BCRL. Patients with any of these three risk factors may benefit from early intervention for BCRL. In addition, we demonstrated that early physiotherapy coupled with an educational program reduced the risk of BCRL. A higher percentage of the patients in Groups B and C received MRM, an aggressive procedure, whereas a higher percentage of those in Group A received the less aggressive $\mathrm{BCS}$ or simple mastectomy (Table 1). Therefore, patients in Groups B and C were at a higher risk of developing BCRL than those in Group A. However, our analysis showed that Group $\mathrm{C}$ exhibited the lowest lymphedema occurrence rate, indicating the beneficial effects of early physiotherapy and education on BCRL. By contrast, Group A (ie, no intervention) exhibited the highest lymphedema occurrence rate. The potential benefits of early education alone (Group B) versus no intervention (Group A) may have been obscured by the difference in the surgery type between the groups. Consequently, patient education was not an outcome factor for BCRL in the multivariate analysis.

Although some risk factors for BCRL are not modifiable, others are potentially preventable through patient education and physiotherapy. Their roles in lymphedema control are discussed as follows.

\section{Effect of educational program}

An educational program may increase the awareness of lymphedema and reduce the risk of BCRL through lifestyle modifications. A study of 136 breast cancer survivors demonstrated that patients who received lymphedema information reported significantly fewer symptoms and more practice of risk-reduction measures than those who did not. ${ }^{23}$ In this study, however, we were unable to demonstrate the benefits of an educational program alone in preventing BCRL. One possible explanation is that patients did not implement the program's advice into their daily lives. Poor adherence to lymphedema self-care programs is a major impediment to treatment success. ${ }^{24} \mathrm{~A}$ prospective study showed that the average adherence to ten BCRL self-care modalities was suboptimal: only $31 \%$ of patients had $\geq 75 \%$ adherence over a 12 -month period. ${ }^{25}$ Some risk-reduction advice, such as avoiding venipuncture and blood pressure cuffs, are based on expert opinion and lack evidential support. ${ }^{26,27}$ Such advice (as well as other home-care programs) might become too complex and burdensome for breast cancer survivors to follow and maintain, leading to poor compliance. The method to deliver the educational materials is another issue. 
Table 3 Crude HRs for the occurrence of lymphedema following breast cancer surgery

\begin{tabular}{|c|c|c|}
\hline Variable & $\begin{array}{l}\text { Crude HR } \\
\text { (95\% Cls) }\end{array}$ & $P$-value \\
\hline \multicolumn{3}{|l|}{ Intervention } \\
\hline No education nor physiotherapy & $\mathrm{I} .00$ (ref) & \\
\hline Education only & $0.82(0.6 \mathrm{I}-\mathrm{I} . \mathrm{II})$ & 0.195 \\
\hline Physiotherapy and education & $0.39(0.20-0.76)$ & 0.005 \\
\hline \multicolumn{3}{|l|}{ Age group (years) } \\
\hline$<50$ & $\mathrm{I} .00$ (ref) & \\
\hline $50-65$ & $\mathrm{I} .02(0.75-\mathrm{I} .4 \mathrm{I})$ & $0.88 \mathrm{I}$ \\
\hline$>65$ & $1.20(0.80-1.8 I)$ & 0.376 \\
\hline \multicolumn{3}{|l|}{ BMI $\left(\mathrm{kg} / \mathrm{m}^{2}\right)$} \\
\hline$<27$ & $\mathrm{I} .00$ (ref) & \\
\hline$\geq 27$ & $1.47(1.06-2.05)$ & 0.022 \\
\hline \multicolumn{3}{|l|}{ Menstrual status } \\
\hline No menopause & $\mathrm{I} .00$ (ref) & \\
\hline Menopause & $1.09(0.82-1.45)$ & 0.556 \\
\hline \multicolumn{3}{|l|}{ TNM stage } \\
\hline $0-2$ & $\mathrm{I} .00(\mathrm{ref})$ & \\
\hline 3 & $2.04(1.52-2.74)$ & $<0.001$ \\
\hline \multicolumn{3}{|l|}{ Histologic grade } \\
\hline 1 & $\mathrm{I} .00$ (ref) & \\
\hline 2 & $1.14(0.76-1.71)$ & 0.541 \\
\hline 3 & $\mathrm{I} .27(0.8 \mathrm{I}-2.02)$ & 0.301 \\
\hline \multicolumn{3}{|l|}{ Axillary lymph node invasion } \\
\hline Negative & $1.00(\mathrm{ref})$ & \\
\hline Positive & $2.15(1.60-2.87)$ & $<0.001$ \\
\hline \multicolumn{3}{|l|}{ Tumor size $(\mathrm{cm})$} \\
\hline$<2$ & $\mathrm{I} .00(\mathrm{ref})$ & \\
\hline $2-5$ & $\mathrm{I} .06(0.78-1.45)$ & 0.700 \\
\hline$>5$ & $2.00(1.31-3.06)$ & 0.001 \\
\hline \multicolumn{3}{|l|}{ Surgery type } \\
\hline BCS & 1.00 (ref) & \\
\hline Simple mastectomy & $1.09(0.43-2.77)$ & 0.859 \\
\hline MRM & $1.33(0.93-1.90)$ & 0.116 \\
\hline \multicolumn{3}{|c|}{ Number of dissected axillary lymph nodes } \\
\hline$\leq 20$ & $\mathrm{I} .00$ (ref) & \\
\hline$>20$ & $1.60(1.20-2.13)$ & 0.001 \\
\hline \multicolumn{3}{|l|}{ Adjuvant R/T } \\
\hline No & 1.00 (ref) & \\
\hline Yes & $1.99(1.49-2.67)$ & $<0.001$ \\
\hline \multicolumn{3}{|l|}{ Adjuvant $\mathrm{C} / \mathrm{T}$} \\
\hline No & $\mathrm{I} .00$ (ref) & \\
\hline Yes & $2.17(1.32-3.57)$ & 0.002 \\
\hline
\end{tabular}

Abbreviations: $\mathrm{HR}$, hazard ratio; $\mathrm{Cl}$, confidence interval; ref, reference; $\mathrm{BMI}$, body mass index; $B C S$, breast-conserving surgery; MRM, modified radical mastectomy; R/T, radiation therapy; $\mathrm{C} / \mathrm{T}$, chemotherapy; TNM, Classification of Malignant Tumors.

The timing, frequency, and delivery method of the riskreduction advice, as well as the people who deliver it, may also be critical factors. ${ }^{28}$ Further study is required to establish evidence-based recommendations regarding risk reduction and to investigate the optimal method for delivering educational materials to breast cancer patients.
Table 4 Adjusted HRs for the occurrence of lymphedema following breast cancer surgery

\begin{tabular}{|c|c|c|}
\hline Variable & $\begin{array}{l}\text { Adjusted HR } \\
(95 \% \mathrm{Cls})\end{array}$ & $P$-value* \\
\hline \multicolumn{3}{|l|}{ Intervention } \\
\hline No education nor physiotherapy & $\mathrm{I} .00$ (ref) & \\
\hline Education only & $0.78(0.58-1.05)$ & 0.096 \\
\hline Physiotherapy and education & $0.35(0.18-0.67)$ & 0.002 \\
\hline \multicolumn{3}{|l|}{ BMI $\left(\mathrm{kg} / \mathrm{m}^{2}\right)$} \\
\hline$<27$ & $\mathrm{I} .00$ (ref) & \\
\hline$\geq 27$ & $1.26(0.90-1.77)$ & 0.178 \\
\hline \multicolumn{3}{|l|}{ TNM stage } \\
\hline $0-2$ & $1.00(\mathrm{ref})$ & \\
\hline 3 & $1.19(0.79-1.80)$ & 0.399 \\
\hline \multicolumn{3}{|l|}{ Axillary lymph node invasion } \\
\hline Negative & 1.00 (ref) & \\
\hline Positive & $1.55(1.06-2.28)$ & 0.025 \\
\hline \multicolumn{3}{|l|}{ Tumor size $(\mathrm{cm})$} \\
\hline$<2$ & 1.00 (ref) & \\
\hline $2-5$ & $0.80(0.57-I .12)$ & 0.185 \\
\hline$>5$ & $1.17(0.71-1.91)$ & 0.542 \\
\hline \multicolumn{3}{|c|}{ Number of dissected axillary lymph nodes } \\
\hline$\leq 20$ & $1.00(\mathrm{ref})$ & \\
\hline$>20$ & $1.40(1.05-1.88)$ & 0.024 \\
\hline \multicolumn{3}{|l|}{ Adjuvant R/T } \\
\hline No & $\mathrm{I} .00($ ref $)$ & \\
\hline Yes & $1.53(1.1 I-2.11)$ & 0.010 \\
\hline \multicolumn{3}{|l|}{ Adjuvant C/T } \\
\hline No & $\mathrm{I} .00$ (ref) & \\
\hline Yes & $\mathrm{I} .42(0.83-2.4 \mathrm{I})$ & 0.200 \\
\hline
\end{tabular}

Note: *The model was adjusted by the variables with $P<0.05$ in the univariate analysis.

Abbreviations: HR, hazard ratio; $\mathrm{Cl}$, confidence interval; ref, reference; $\mathrm{BMI}$, body mass index; $\mathrm{R} / \mathrm{T}$, radiation therapy; $\mathrm{C} / \mathrm{T}$, chemotherapy; TNM, Classification of Malignant Tumors.

\section{Effect of physiotherapy}

In this study, physiotherapy, which included scar massage and upper-limb and shoulder exercises, combined with patient education reduced the risk of BCRL by $65 \%$ $(\mathrm{HR}=0.35)$ (Table 4). This finding is comparable with those of two previous studies. ${ }^{15,16} \mathrm{~A}$ study in Italy compared two groups of breast cancer patients: the first group $(n=25)$ was provided information on lymphedema presurgery, and the second group $(\mathrm{n}=58)$ received information on lymphedema presurgery and an early rehabilitation program postsurgery; the program included deep breathing, relaxation, neck muscle stretching, and shoulder exercise. At Day 180, 5.3\% of the patients in the second group exhibited a lower incidence of BCRL, whereas that in the first group was $20.0 \%(P=0.036) .{ }^{16}$ Another study in Spain randomized breast cancer patients to receive either early physiotherapy and patient education $(n=60)$ or only education $(n=60) .{ }^{15}$ Their physiotherapy programs were similar to ours, including scar massage and 


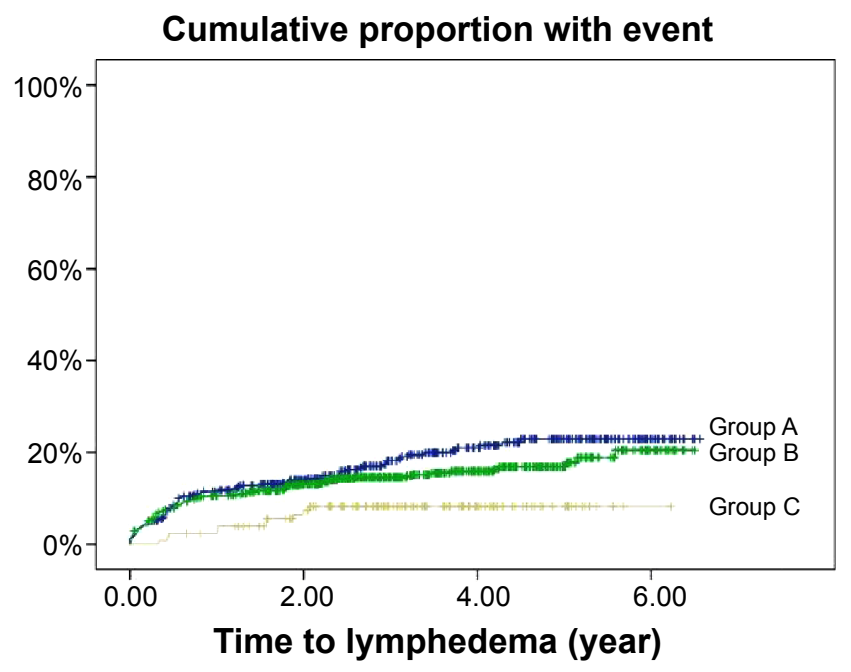

Figure I Kaplan-Meier plot of lymphedema proportions estimated for patients on different treatment schedules.

Notes: Group A: patients who received neither the educational program nor physiotherapy postsurgery; Group B: patients who received only the educational program; and Group C: patients who received both the educational program and physiotherapy.

shoulder exercises, as well as MLD, which our study did not include. The study found that patients receiving both physiotherapy and education had a lower lymphedema occurrence rate $(6.8 \%)$ at the 1-year follow-up compared with those receiving education alone $(24.5 \%) .{ }^{15}$ The authors partially attributed the benefits of physiotherapy to MLD. However, the findings of the study conducted in Italy and those from our study indicate that scar massage and shoulder exercise programs might play active roles in reducing the risk for BCRL because both studies did not include MLD. Scar massage induces matrix remodeling of scar tissue, ${ }^{29,30}$ and exercise can compress the lymphatic vessels, ${ }^{31}$ thereby improving lymphatic drainage and reducing the occurrence of lymphedema. Furthermore, a study has indicated that MLD had no major effect in preventing lymphedema. ${ }^{32}$

\section{Limitations}

The advantages of this study are that it involved a larger sample and a longer follow-up period compared with the two discussed previous prospective studies. ${ }^{15,16}$ However, our study had limitations. First, this was a hospital-based retrospective cohort study. The hospital sample comprised only patients in a designated region, rendering the generalizability of results a major challenge. Second, the cancer registry may not have included all the variables of outcome significance; therefore, estimates from the multivariate analysis are subject to confounding bias from these unavailable covariates, or to residual confounding of the measured variables. However, we endeavored to include most clinically critical variables into our analyses through medical chart reviews. Third, we were unable to access information from other hospitals; hence, we could not exclude the possibility that patients in Group A (no intervention) or Group B (educational program only) received physiotherapy programs outside our hospital. Fourth, the median duration until lymphedema onset was marginally longer in Group C (1.29 years) than in Groups A ( 0.55 years) and B ( 0.44 years). Physiotherapy coupled with patient education might only delay the onset rather than prevent BCRL. A longer follow-up period could facilitate answering this question. Finally, the decision to request rehabilitation services was determined by the surgeon rather than through a randomized process. Surgeons might think that patients who have received a conservative procedure do not require rehabilitation. Such bias might explain why the surgery type was distributed unevenly among Groups A-C.

\section{Conclusion}

Patient education that begins within the first week postsurgery and is followed by physiotherapy is effective in reducing the risk of lymphedema in women who undergo breast cancer surgery with ALND.

\section{Disclosure}

The authors have no financial relationships to disclose with regard to this study. The authors report no conflicts of interest in this work.

\section{References}

1. DiSipio T, Rye S, Newman B, Hayes S. Incidence of unilateral arm lymphoedema after breast cancer: a systematic review and meta-analysis. Lancet Oncol. 2013;14(6):500-515.

2. Petrek JA, Senie RT, Peters M, Rosen PP. Lymphedema in a cohort of breast carcinoma survivors 20 years after diagnosis. Cancer. 2001;92(6): 1368-1377.

3. Hayes SC, Johansson K, Stout NL, et al. Upper-body morbidity after breast cancer: incidence and evidence for evaluation, prevention, and management within a prospective surveillance model of care. Cancer. 2012;118(8 suppl):2237-2249.

4. Mak SS, Yeo W, Lee YM, et al. Predictors of lymphedema in patients with breast cancer undergoing axillary lymph node dissection in Hong Kong. Nurs Res. 2008;57(6):416-425.

5. Soran A, D’Angelo G, Begovic M, et al. Breast cancer-related lymphedema - what are the significant predictors and how they affect the severity of lymphedema? Breast J. 2006;12(6):536-543.

6. van der Veen P, De Voogdt N, Lievens P, Duquet W, Lamote J, Sacre R. Lymphedema development following breast cancer surgery with full axillary resection. Lymphology. 2004;37(4):206-208.

7. Paskett ED, Naughton MJ, McCoy TP, Case LD, Abbott JM. The epidemiology of arm and hand swelling in premenopausal breast cancer survivors. Cancer Epidemiol Biomarkers Prev. 2007;16(4):775-782. 
8. Tsai RJ, Dennis LK, Lynch CF, Snetselaar LG, Zamba GK, Scott-Conner C. The risk of developing arm lymphedema among breast cancer survivors: a meta-analysis of treatment factors. Ann Surg Oncol. 2009;16(7):1959-1972.

9. Avraham T, Clavin NW, Daluvoy SV, et al. Fibrosis is a key inhibitor of lymphatic regeneration. Plast Reconstr Surg. 2009;124(2): $438-450$.

10. Blum KS, Proulx ST, Luciani P, Leroux JC, Detmar M. Dynamics of lymphatic regeneration and flow patterns after lymph node dissection. Breast Cancer Res Treat. 2013;139(1):81-86.

11. Stamatakos M, Stefanaki C, Kontzoglou K. Lymphedema and breast cancer: a review of the literature. Breast Cancer. 2011;18(3):174-180.

12. Lin S, Kim J, Lee MJ, et al. Prospective transcriptomic pathway analysis of human lymphatic vascular insufficiency: identification and validation of a circulating biomarker panel. PLoS One. 2012;7(12):e52021.

13. Fialka-Moser V, Korpan M, Varela E, et al. The role of physical and rehabilitation medicine specialist in lymphoedema. Ann Phys Rehabil Med. 2013;56(5):396-410.

14. Chan DN, Lui LY, So WK. Effectiveness of exercise programmes on shoulder mobility and lymphoedema after axillary lymph node dissection for breast cancer: systematic review. J Adv Nurs. 2010;66(9):1902-1914.

15. Torres Lacomba M, Yuste Sánchez MJ, Zapico Goñi A, et al. Effectiveness of early physiotherapy to prevent lymphoedema after surgery for breast cancer: randomised, single blinded, clinical trial. $B M J$. 2010;340:b5396.

16. Scaffidi M, Vulpiani MC, Vetrano M, et al. Early rehabilitation reduces the onset of complications in the upper limb following breast cancer surgery. Eur J Phys Rehabil Med. 2012;48(4):601-611.

17. Harris SR, Hugi MR, Olivotto IA, Levine M; Steering Committee for Clinical Practice Guidelines for the Care and Treatment of Breast Cancer. Clinical practice guidelines for the care and treatment of breast cancer: 11. Lymphedema. CMAJ. 2001;164(2):191-199.

18. Position statement of the National Lymphedema Network. Topic: Lymphedema Risk Reduction Practices; 2011. Available from: http://www. lymphnet.org/pdfDocs/nlnriskreduction.pdf. Accessed December 1, 2014.

19. Internaltional Society of Lymphology. The diagnosis and treatment of peripheral lymphedema: 2013 Consensus Document of the International Society of Lymphology. Lymphology. 2013;46(1):1-11.
20. American Joint Commmittee on Cancer. AJCC Cancer Staging Manual. 6th ed. Heidelberg: Springer; 2002.

21. Galea MH, Blamey RW, Elston CE, Ellis IO. The Nottingham prognostic index in primary breast cancer. Breast Cancer Res Treat. 1992;22(3):207-219.

22. Kim M, Kim SW, Lee SU, et al. A model to estimate the risk of breast cancer-related lymphedema: combinations of treatment-related factors of the number of dissected axillary nodes, adjuvant chemotherapy, and radiation therapy. Int J Radiat Oncol Biol Phys. 2013;86(3):498-503.

23. Fu MR, Chen CM, Haber J, Guth AA, Axelrod D. The effect of providing information about lymphedema on the cognitive and symptom outcomes of breast cancer survivors. Ann Surg Oncol. 2010;17(7):1847-1853.

24. Vignes S, Porcher R, Arrault M, Dupuy A. Factors influencing breast cancer-related lymphedema volume after intensive decongestive physiotherapy. Support Care Cancer. 2011;19(7):935-940.

25. Brown JC, Cheville AL, Tchou JC, Harris SR, Schmitz KH. Prescription and adherence to lymphedema self-care modalities among women with breast cancer-related lymphedema. Support Care Cancer. 2014;22(1):135-143.

26. Cemal Y, Pusic A, Mehrara BJ. Preventative measures for lymphedema: separating fact from fiction. J Am Coll Surg. 2011;213(4):543-551.

27. Showalter SL, Brown JC, Cheville AL, Fisher CS, SataloffD, SchmitzKH. Lifestyle risk factors associated with arm swelling among women with breast cancer. Ann Surg Oncol. 2013;20(3):842-849.

28. Nielsen I, Gordon S, Selby A. Breast cancer-related lymphoedema risk reduction advice: a challenge for health professionals. Cancer Treat Rev. 2008;34(7):621-628.

29. Chan MW, Hinz B, McCulloch CA. Mechanical induction of gene expression in connective tissue cells. Methods Cell Biol. 2010;98: 178-205.

30. Renò F, Sabbatini M, Lombardi F, et al. In vitro mechanical compression induces apoptosis and regulates cytokines release in hypertrophic scars. Wound Repair Regen. 2003;11(5):331-336.

31. Tartaglione G, Pagan M, Morese R, et al. Intradermal lymphoscintigraphy at rest and after exercise: a new technique for the functional assessment of the lymphatic system in patients with lymphoedema. Nucl Med Commun. 2010;31(6):547-551.

32. Reul-Hirche H. Manual lymph drainage when added to advice and exercise may not be effective in preventing lymphoedema after surgery for breast cancer. J Physiother. 2011;57(4):258. 


\section{Supplementary material}

Table SI Physiotherapy program

\begin{tabular}{|c|c|}
\hline Type of rehabilitation & Methods \\
\hline \multirow[t]{2}{*}{ Breathing exercise } & Purpose: to increase chest wall mobility before removing the drainage tube \\
\hline & Methods: deep breathing and pursed lip breathing exercises at least 6 times a day \\
\hline \multirow[t]{2}{*}{ Postsurgical positioning } & Purpose: to reduce wound edema postsurgery before removing the drainage tube \\
\hline & Methods: keep the arm elevated above the heart \\
\hline Massaging of scar tissue & Purpose: to soften scar tissue \\
\hline \multirow[t]{4}{*}{ and stretching of the soft tissue } & Methods: (I) use the pads of the fingers to massage the scar and the surrounding tissue \\
\hline & in circular, vertical, and horizontal motions; and (2) passive and active stretching \\
\hline & and transverse strain of the major and minor pectoral muscles \\
\hline & Duration: average $10-15$ minutes \\
\hline \multirow[t]{4}{*}{ Mobilization of the shoulders } & Purpose: to restore range of shoulder motion \\
\hline & Methods: active or passive mobilization of the shoulders in all planes of motion, \\
\hline & including flexion, extension, adduction, abduction, and internal and external rotation \\
\hline & Duration: average 5-10 minutes per section \\
\hline \multirow[t]{11}{*}{ Shoulder and upper extremity exercise } & Purpose: (I) to improve muscle flexibility and strength; (2) to improve \\
\hline & range of motion; and (3) to facilitate lymphatic transport \\
\hline & Methods: (I) Before removing the drainage tube: (a) hand and finger exercise: make \\
\hline & a fist and release pressure while turning the hand; and (b) wrist and elbow exercise: \\
\hline & flexion and extension. (2) After removing the drainage tube and before removing the \\
\hline & stitches: (a) shoulder shrugs and shoulder rolls; and (b) internal and external rotation \\
\hline & of the shoulder. (3) After removing the stitches: (a) shoulder raise; (b) arm swing; \\
\hline & (c) side bending and body rotations; (d) lifting the arm above the head; (e) walking \\
\hline & the fingers up a wall and sideways; and ( $f$ ) chest wall stretch \\
\hline & Duration: average $10-15$ minutes ( 10 repetitions in each set), $2-3$ times per day \\
\hline & Patients are asked to perform exercises from the program twice per day at home \\
\hline
\end{tabular}

Therapeutics and Clinical Risk Management

\section{Publish your work in this journal}

Therapeutics and Clinical Risk Management is an international, peerreviewed journal of clinical therapeutics and risk management, focusing on concise rapid reporting of clinical studies in all therapeutic areas, outcomes, safety, and programs for the effective, safe, and sustained use of medicines. This journal is indexed on PubMed Central, CAS,
EMBase, Scopus and the Elsevier Bibliographic databases. The manuscript management system is completely online and includes a very quick and fair peer-review system, which is all easy to use. Visit http://www.dovepress.com/testimonials.php to read real quotes from published authors.

Submit your manuscript here: http://www.dovepress.com/therapeutics-and-clinical-risk-management-journal 